Supplement of Biogeosciences, 15, 6087-6104, 2018 https://doi.org/10.5194/bg-15-6087-2018-supplement (C) Author(s) 2018. This work is distributed under the Creative Commons Attribution 4.0 License.

(c) (1)

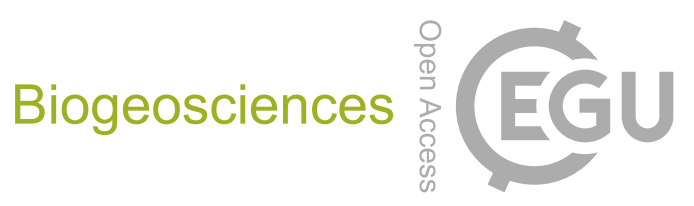

Supplement of

\title{
Life cycle of bamboo in the southwestern Amazon and its relation to fire events
}

Ricardo Dalagnol et al.

Correspondence to: Ricardo Dalagnol (ricds@ hotmail.com)

The copyright of individual parts of the supplement might differ from the CC BY 4.0 License. 
Table 1. Dates of TM/Landsat-5 images used for validation of bamboo die-off predictions. The date of each image (YYYY-MM-DD) is presented for each path-row (World Reference System 2) in the columns.

\begin{tabular}{ccccccc}
\hline \hline Path-Row & $\mathbf{0 0 6 - 0 6 5}$ & $\mathbf{0 0 3 - 0 6 6}$ & $\mathbf{0 0 2 - 0 6 7}$ & $\mathbf{0 0 3 - 0 6 7}$ & $\mathbf{0 0 5 - 0 6 7}$ & $\mathbf{0 0 3 - 0 6 8}$ \\
\hline & $1985-06-28$ & $1985-07-09$ & $1985-09-04$ & $1985-08-26$ & $1985-07-23$ & $1985-07-09$ \\
& $1986-08-02$ & $1986-07-28$ & $1986-08-06$ & $1986-09-30$ & $1986-07-26$ & $1986-10-16$ \\
& $1987-08-05$ & $1987-08-16$ & $1987-08-25$ & $1987-08-16$ & $1987-08-14$ & $1987-08-16$ \\
& $1988-08-07$ & $1988-07-17$ & $1988-08-11$ & $1988-08-18$ & $1988-07-15$ & $1988-06-15$ \\
& $1989-08-26$ & $1989-07-20$ & $1989-08-14$ & $1989-09-22$ & $1989-09-04$ & $1989-08-21$ \\
& $1990-04-23$ & $1990-07-07$ & $1990-09-18$ & $1990-07-23$ & $1990-06-19$ & $1990-08-24$ \\
& $1991-06-13$ & $1991-07-26$ & $1991-07-27$ & $1991-07-26$ & $1991-07-08$ & $1991-07-10$ \\
Dates & $1992-10-05$ & $1992-08-13$ & $1992-07-21$ & $1992-07-28$ & $1992-08-27$ & $1992-07-28$ \\
& $1993-08-05$ & $1993-09-01$ & $1993-08-25$ & $1993-06-13$ & $1993-08-14$ & $1993-06-13$ \\
& $1994-07-23$ & $1994-07-18$ & $1994-07-27$ & $1994-07-18$ & $1994-06-30$ & $1994-07-18$ \\
& $1995-08-27$ & $1995-08-22$ & $1995-07-30$ & $1995-08-22$ & $1995-06-17$ & $1995-07-05$ \\
& $1996-07-12$ & $1996-07-23$ & $1996-08-01$ & $1996-07-23$ & $1996-07-05$ & $1996-07-23$ \\
& $1997-09-01$ & $1997-07-10$ & $1997-07-19$ & $1997-07-10$ & $1997-07-24$ & $1997-08-27$ \\
& $1998-07-18$ & $1998-07-13$ & $1998-09-24$ & $1998-08-30$ & $1998-09-13$ & $1998-07-13$ \\
& $1999-08-06$ & $1999-08-01$ & $1999-08-10$ & $1999-08-17$ & $1999-07-30$ & $1999-08-17$ \\
& $2000-10-11$ & $2000-07-18$ & $2000-07-27$ & $2000-07-18$ & $2000-09-02$ & $2000-09-04$ \\
\hline
\end{tabular}




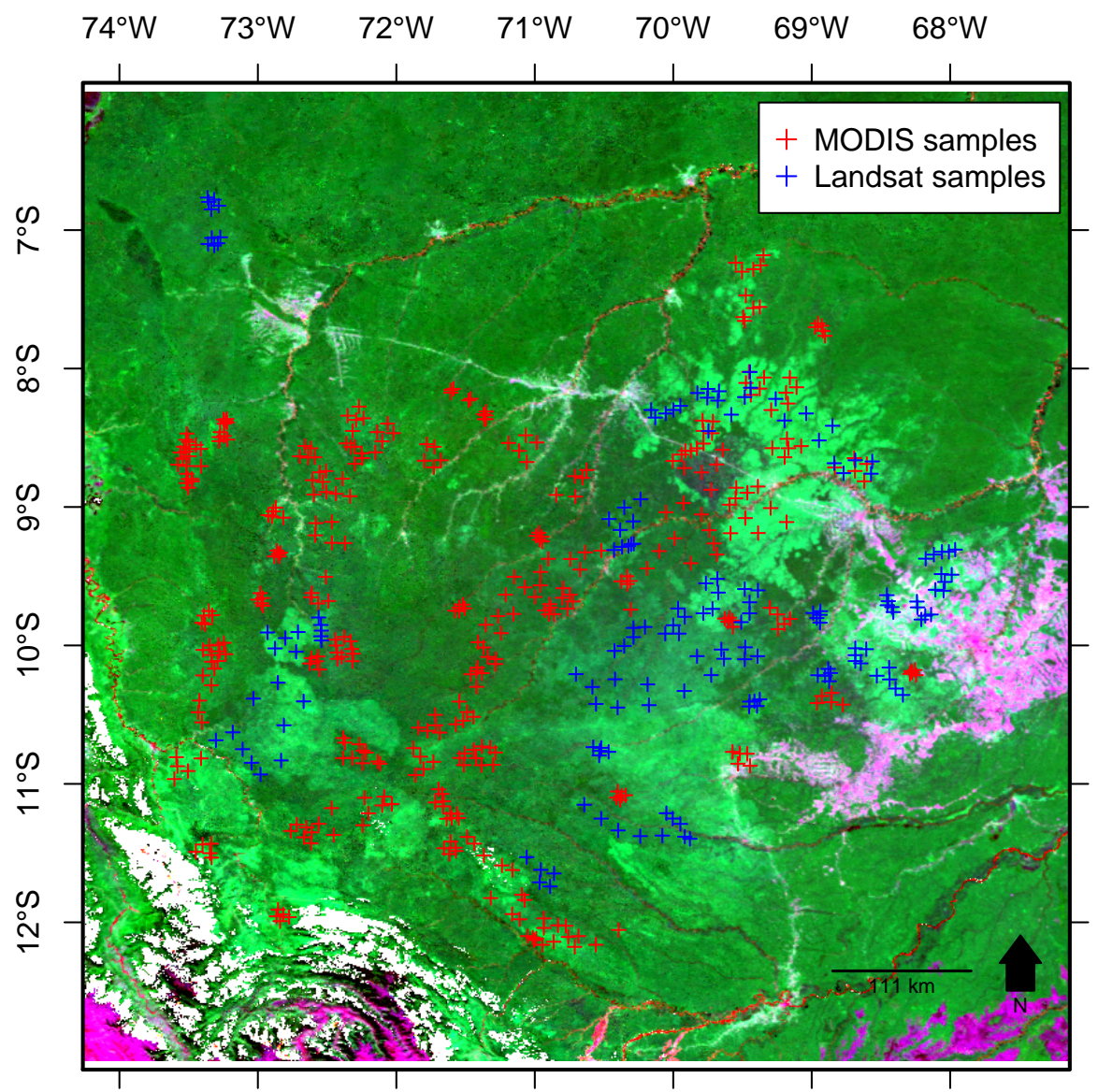

Figure 1. Spatial distribution of validation samples obtained from MODIS (2001-2017) imagery in red and Landsat (1985-2000) imagery in blue. The image at background is a false-color composite from MODIS (MAIAC) images of bands 1 (Red), 2 (NIR) and 6 (shortwave infrared), in RGB, respectively, in August 2015. 


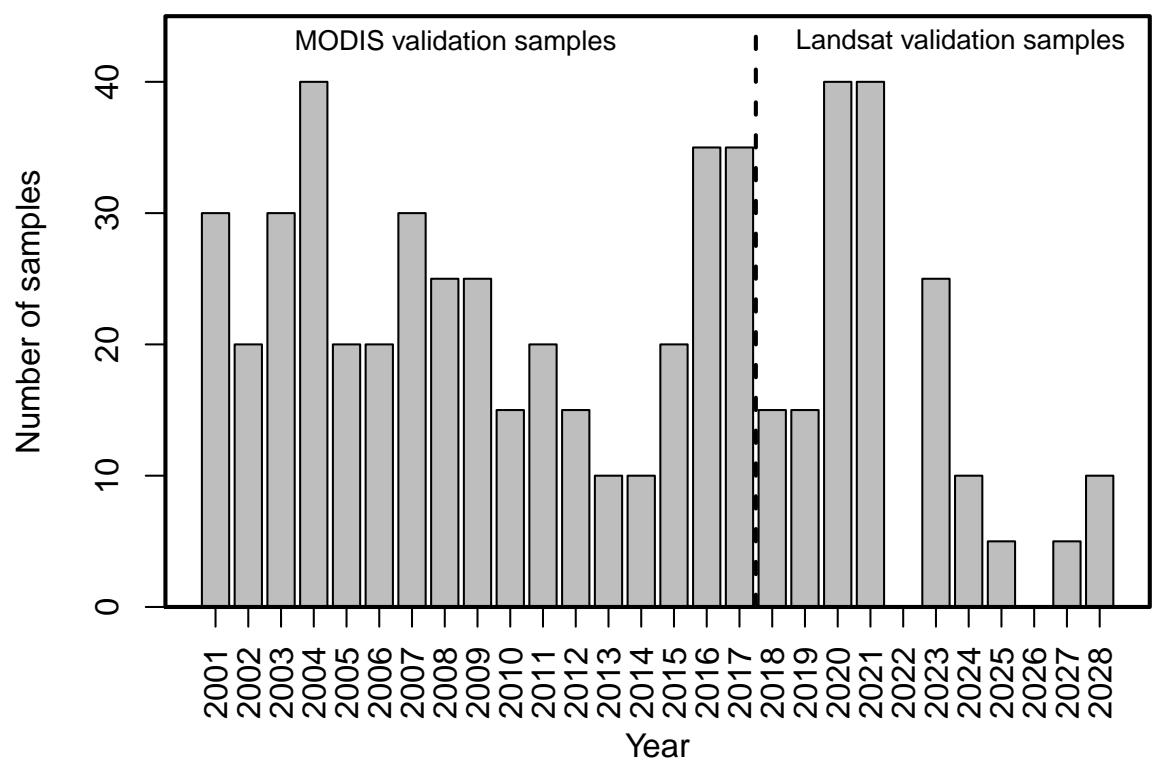

Figure 2. Temporal distribution of validation samples for bamboo die-off detection (2001-2017) from MODIS imagery; and for bamboo die-off prediction (2018-2028) from Landsat imagery. 


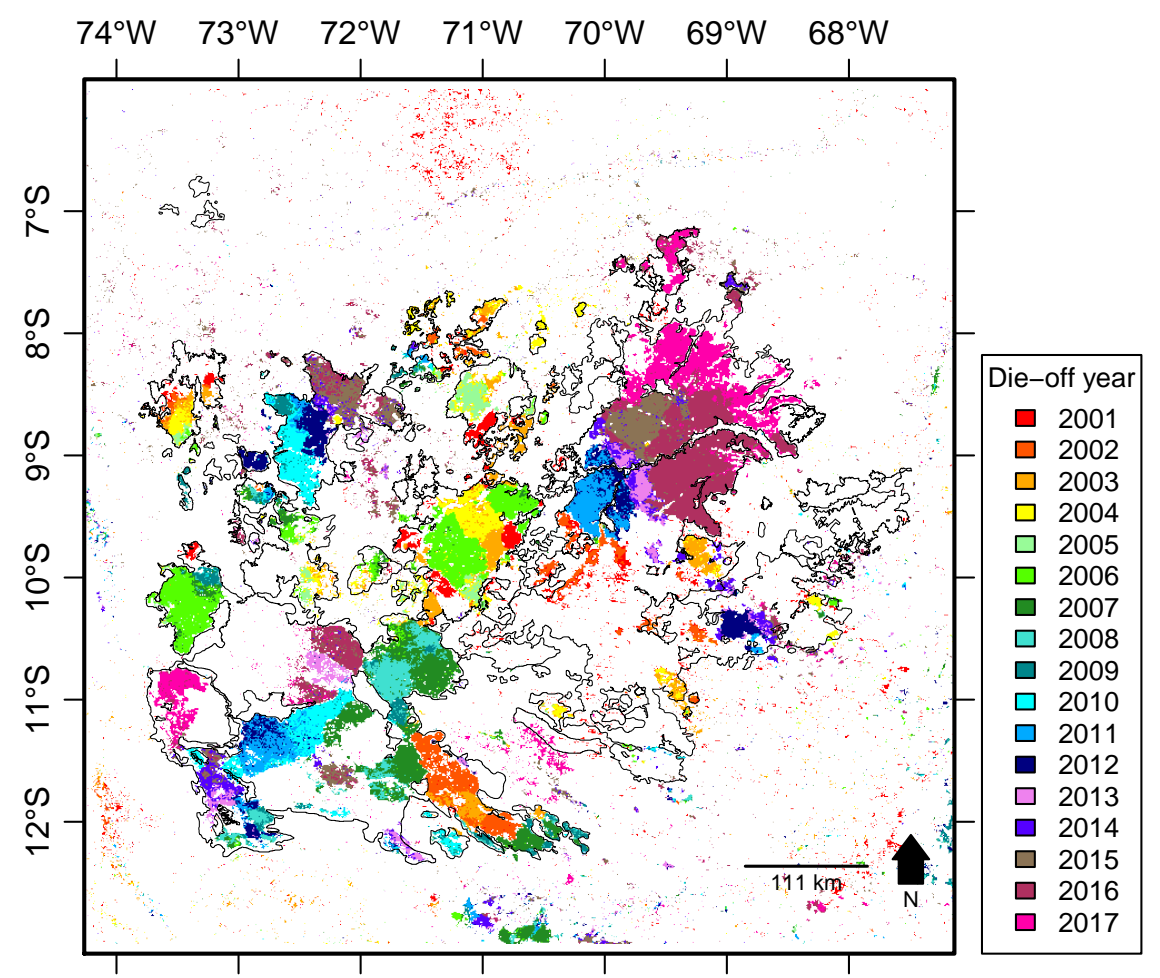

Figure 3. Bamboo die-off during 2001-2017 from the combined detections using MODIS (MAIAC) NIR-1 and NIR-2 and the bilinear model. The black lines indicate the perimeter of the bamboo-dominated areas delineated in a previous study (Carvalho et al., 2013). 


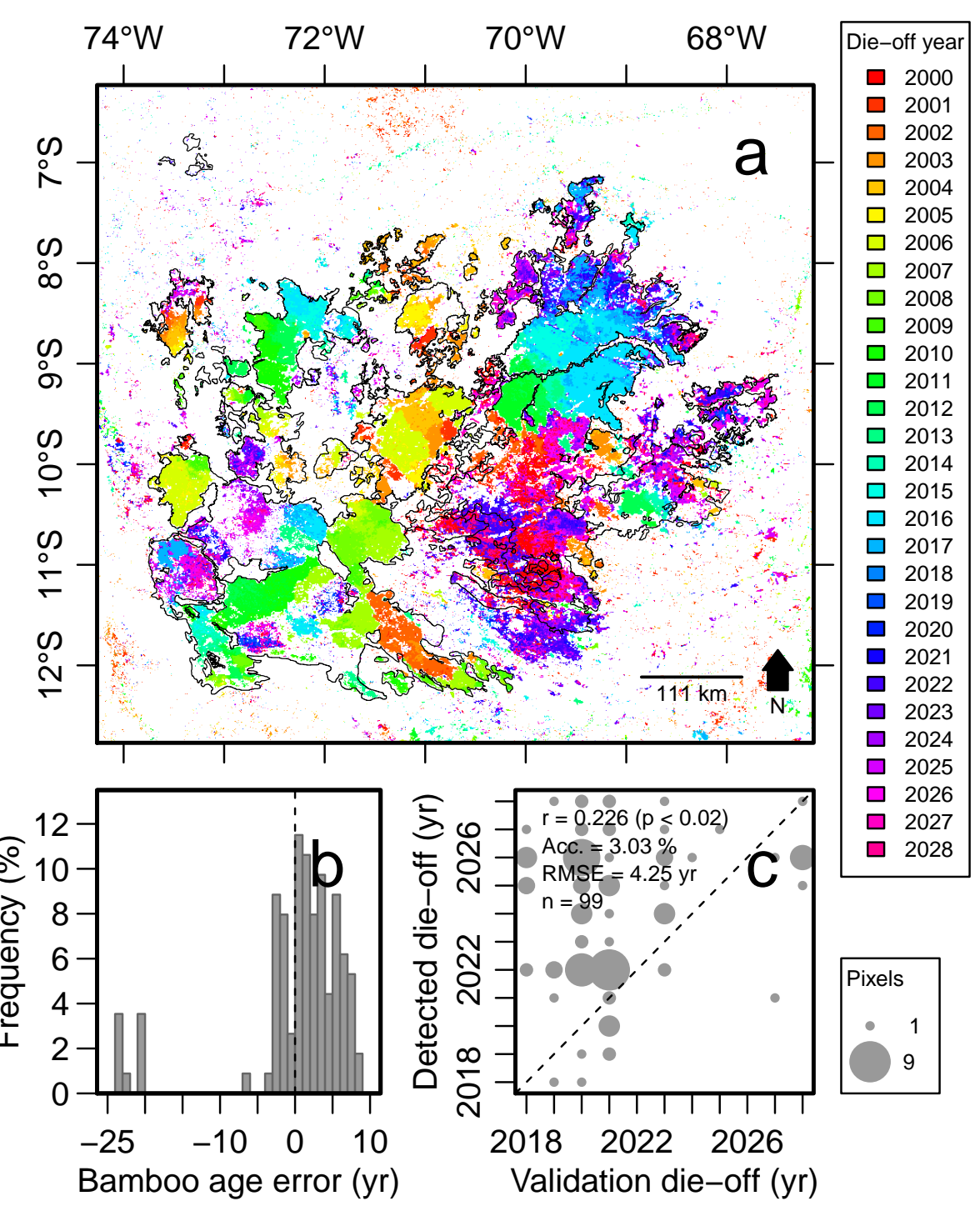

Figure 4. MODIS bamboo die-off prediction map from 2000 to 2028 using the empirical curves of the near infrared 2 (NIR-2) reflectance as a function of bamboo cohort age (a). Validation between predicted die-off (2017-2028) and visual interpreted die-off from previous life cycle in Landsat false-color composites (1985-2000) (c) and residuals distribution (b). The dashed line represents the 1:1 line in (c) and age residual $=0$ in (b). Size of circles is related to the number of pixels that hit the same observed/estimate die-off year. 